these patients remain asymptomatic, and left sided pleural or pulmonary nodules may be discovered many years after the episode of trauma. Pulmonary nodules are often malignant, and it is commonly accepted that they should be considered malignant unless proven otherwise. Alertness to the possibility of thoracic splenosis can lead to confirmation of the diagnosis by the use of radionuclide scanning, and so prevent unnecessary thoracotomy and rendering the patient asplenic.

1 Shaw AFB, Shafi A. Traumatic autoplastic transplantation of splenic tissue in man with observations on the late results of splenectomy in six cases. 7 Pathol 1937;45. 215-35.

2 Roucos S, Tabet G, Jebara VA, Ghossain MA, Biagini J,
Saade B. Thoracic splenosis: case report and literature review. I Thorac Cardiovasc Surg 1990;99:361-3.

3 Hietala E-M, Hermunen H, Kostiainen S. Intrathoracic splenosis: report of a case simulating esophageal leiomyoma. Scand f Thorac Cardiovasc Surg 1993;27:61-3.

4 Scales FE, Lee ME. Nonoperative diagnosis of intrathoracic splenosis. AfR 1983;141:1273-4.

5 Moncada R, Williams V, Fareed J, Messmore H. Thoracic splenosis. $A F R$ 1985;144:705-6.

6 Schiff RG, Leonidas J, Schende A, Lanzkowski P. The noninvasive diagnosis of intrathoracic splenosis using technetium- $99 \mathrm{~m}$ heat-damaged red blood cells. Clin Nucl Med 1987;12:785-7.

7 Hart CM, Clore FC, Hood CI. Intrathoracic splenosis. Chest 1990;97:1024.

8 Sass W, Bergholz M, Kehl A, Seifert J, Hamelmann H. Overwhelming infection after splenectomy in spite of some spleen remaining. Klin Wochenschr 1983;61:1075-9.

9 Widmann WD, Laubscher FA. Splenosis: a disease or a beneficial condition? Arch Surg 1971;102:152-8.

10 Pearson HA, Johnston D, Smith KA, Touloukian RJ. The born again spleen: return of splenic function after splenectomy for trauma. N Engl ₹ Med 1978;298:1389-92.

\title{
Effects of nedocromil sodium in the treatment of non-allergic subjects with chronic obstructive pulmonary disease
}

\author{
Jan W de Jong, Dirkje S Postma, Thomas W van der Mark, Gerard H Koëter
}

Department of Pulmonology, University Hospital, 9713 EZ Groningen, The Netherlands $\mathrm{J}$ W de Jong D S Postma $T$ W van der Mark G H Koëter

Reprint requests to: Professor D S Postma.

Received 8 November 1993 Returned to authors 7 January 1994 Revised version received 10 March 1994 Accepted for publication 27 May 1994

\begin{abstract}
Background - Nedocromil sodium, a nonsteroidal anti-inflammatory drug, is effective in the treatment of asthma. Its efficacy in the treatment of chronic obstructive pulmonary disease (COPD) has not been investigated.

Methods - Fifty four non-allergic patients with COPD were randomised to 10 weeks of treatment with placebo or nedocromil sodium $(4 \times 8 \mathrm{mg} / \mathrm{day})$ in a double blind study.

Results - Nedocromil sodium treatment had no effect on airway responsiveness to histamine, methacholine, and adenosine5 -monophosphate, pulmonary function, and symptom scores. Both patients and clinicians favoured treatment with nedocromil sodium, however, and the number of dropouts (because of exacerbations) was fewer during treatment with the drug. Conclusions - Longer trials will be necessary to assess if nedocromil sodium can reduce the frequency of exacerbations and the decrease in pulmonary function, eventually leading to a better quality of life in patients with COPD.
\end{abstract}

(Thorax 1994;49:1022-1024)

Nedocromil sodium has been shown to be effective in the treatment of patients with al- lergic asthma. ${ }^{1}$ Studies investigating its effects in chronic obstructive pulmonary disease (COPD) are not available. The aim of our study was to investigate the effects of 10 weeks of treatment with nedocromil sodium on airway responsiveness to histamine, methacholine, and adenosine- $5^{\prime}$-monophosphate (AMP), pulmonary function, and clinical symptoms in a group of non-allergic patients with COPD. As anti-inflammatory treatment in COPD is generally accompanied by little or no change in clinical parameters a high dose of nedocromil sodium (arbitrarily determined at $32 \mathrm{mg}$ daily) was chosen.

\section{Methods}

SUBJECTS

All participants were at least 40 years of age and had a diagnosis of COPD based on the recommendations of the American Thoracic Society, ${ }^{2}$ meeting the following criteria: (1) no atopy: negative skin reactions to 18 common aeroallergens, negative specific serum immunoglobulin $\mathrm{E}$ to house dust mite, and peripheral blood eosinophils $<450 / \mathrm{mm}^{3}$; (2) forced expiratory volume in one second $\left(\mathrm{FEV}_{1}\right)>1$ litre and $<70 \%$ predicted and $\mathrm{FEV}_{1}$ after $40 \mu \mathrm{g}$ ipratropium bromide $<80 \%$ predicted; (3) concentration of histamine causing a $20 \%$ decrease 
Mean (SD) characteristics of patients

\begin{tabular}{lcc}
\hline & $\begin{array}{c}\text { Placebo } \\
(n=21)\end{array}$ & $\begin{array}{l}\text { Nedocromil } \\
\text { sodium } \\
(n=27)\end{array}$ \\
\hline Gender (M/F) & $18 / 3$ & $26 / 1$ \\
Age (years) & $61 \cdot 2(1 \cdot 8)$ & $60 \cdot 4(1 \cdot 5)$ \\
Smokers (n) & 10 & 15 \\
Cigarettes/day & $8 \cdot 0(2 \cdot 5)$ & $6 \cdot 9(1 \cdot 7)$ \\
Pack years & $22 \cdot 6(3 \cdot 2)$ & $20 \cdot 7(2 \cdot 3)$ \\
Eosinophils/mm & $147 \cdot 0(28 \cdot 9)$ & $136 \cdot 5(16 \cdot 5)$ \\
Reversibility* & $8 \cdot 4(1 \cdot 2)$ & $6 \cdot 3(0 \cdot 8)$ \\
FEV $(\%$ predicted) & $49 \cdot 2(2 \cdot 5)$ & $50 \cdot 6(2 \cdot 2)$ \\
IVC (\% predicted) & $83 \cdot 8(2 \cdot 9)$ & $80 \cdot 8(2 \cdot 4)$ \\
PC $_{20}$ histamine** & $0 \cdot 2$ & $0 \cdot 2$ \\
PC $_{20}$ methacholine** & $0 \cdot 4$ & $0 \cdot 4$ \\
\hline
\end{tabular}

$\mathrm{FEV}_{1}=$ forced expiratory volume in one second; IVC $=$ inspiratory slow vital capacity.

${ }^{*}$ Reversibility expressed as $\triangle \mathrm{FEV},\left(\%\right.$ predicted). ${ }^{* *}$ Geometric mean $(\mathrm{mg} / \mathrm{ml})$.

of $\mathrm{FEV}_{1}$ from baseline $\left(\mathrm{PC}_{20}\right)<8 \mathrm{mg} / \mathrm{ml}$; (4) no upper respiratory tract infection or exacerbation during six weeks before the start of the study. Patients with asthmatic attacks and wheeze were excluded. The study was approved by the hospital medical ethics committee and all subjects gave their written informed consent.

\section{STUDY DESIGN}

The study comprised a two week single blind placebo baseline, a 10 week double blind active treatment, and a 2 week placebo washout period. Inhaled corticosteroids were stopped two weeks before the start of the study. During the study only bronchodilators were allowed, but were discontinued eight hours before each clinic visit. Nedocromil sodium ( $2 \mathrm{mg} / \mathrm{puff})$ or placebo were given as four inhalations four times daily via a Nebuhaler. At each two week visit lung function $\left(\mathrm{FEV}_{1}\right.$ and inspiratory slow vital capacity (IVC)) was measured with a calibrated water sealed spirometer, and cumulative dose-response histamine and methacholine inhalation provocation tests were performed. Similarly, AMP inhalation provocation tests were performed just before and at the end of the treatment period. ${ }^{3}$ All patients kept a daily diary card using a four point severity scale $(0=$ no symptoms, $3=$ very severe symp-
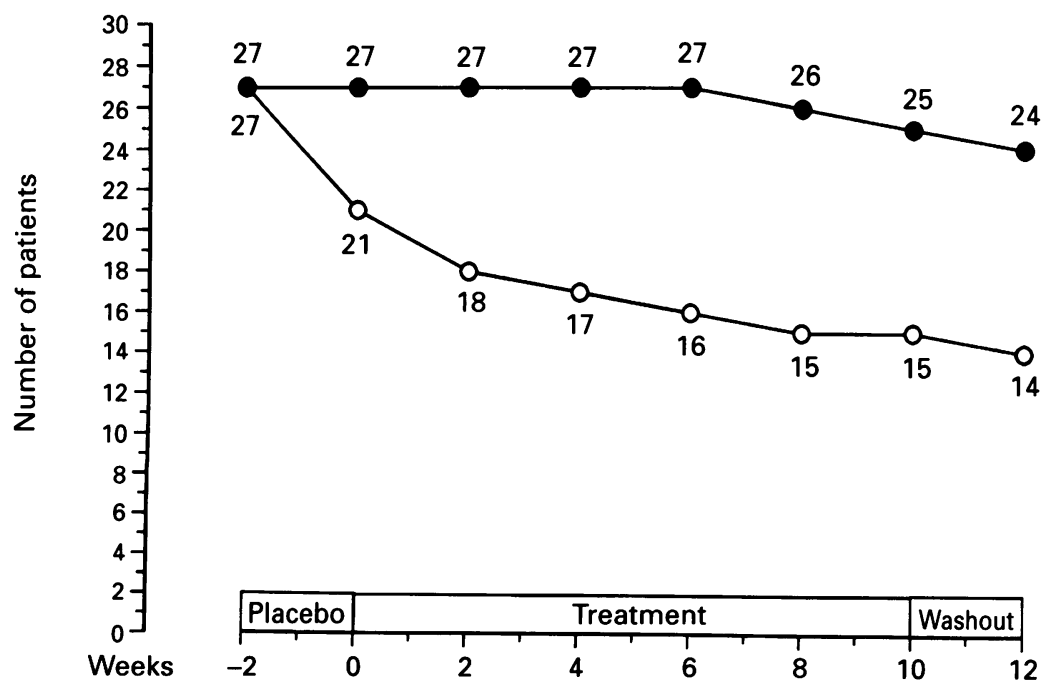

Number of patients during the double blind randomised, placebo controlled study $(\mathrm{O}=$ nedocromil sodium, $\mathrm{O}=$ placebo). During the washout period all patients received placebo. toms) to assess both day and night time dyspnoea scores, cough severity, sputum production, additional bronchodilator medication, and the highest of three measurements of morning and evening peak expiratory flow (PEF) using the mini-Wright peak flow meter.

\section{DATA ANALYSIS}

All $\mathrm{PC}_{20}$ values were analysed after base 2 logarithmic transformation, one log unit being one dose step in concentration. Comparisons of the effects of nedocromil sodium and placebo were made on changes from baseline and the mean treatment effects were calculated from the final eight weeks of the 10 week double blind treatment period, taking into account at least four weeks of treatment. The clinical effects of placebo and nedocromil sodium on pulmonary function, airway responsiveness, and symptom scores were assessed by Student's $t$ tests for grouped values or Mann-Whitney $\mathrm{U}$ tests as appropriate. A survival analysis (Kaplan-Meier with the Mantel-Cox statistic) was performed to compare treatments using the number of days on treatment before withdrawal. Two tailed tests have been used throughout at the $95 \%$ level of significance.

\section{Results}

Fifty four patients with COPD entered the study and were randomised to treatment; six patients dropped out during the baseline period and were excluded from treatment analysis. Twenty one patients started treatment with placebo and 27 with nedocromil sodium (table). Fifteen patients in the placebo group and 21 in the treatment group were taking inhaled corticosteroids before the study (mean daily dose $<700 \mu \mathrm{g}$ in each group $(\mathrm{p}>0.05))$. Six patients withdrew during placebo administration and two during nedocromil sodium $(p<0 \cdot 05)$. During the washout period one patient was withdrawn after placebo and one after nedocromil sodium, all because of an exacerbation of their airways disease (figure).

$\mathrm{FEV}_{1}$ (\% predicted), morning PEF, evening $\mathrm{PEF}$, diurnal peak flow variation, $\mathrm{PC}_{20}$ histamine, $\mathrm{PC}_{20}$ methacholine, $\mathrm{PC}_{20} \mathrm{AMP}$, and all diary card symptom scores were similar for both placebo and nedocromil sodium groups. Taking use of corticosteroids before the treatment as covariable, there was no significant effect on these parameters.

Treatment was considered at least slightly effective in $59 \%$ of the patients receiving nedocromil sodium and in $43 \%$ of those receiving placebo $(p>0.05)$, whereas the clinician (JW de $J)$ considered the treatment at least slightly effective in $63 \%$ of those on nedocromil sodium and $24 \%$ of those on placebo $(p<0.01)$. Side effects during nedocromil sodium and placebo were negligible.

\section{Discussion}

This is the first study to investigate the effects of nedocromil sodium in non-allergic patients with COPD. Following 10 weeks of treatment 
with nedocromil sodium and placebo there were only two treatment differences in favour of nedocromil sodium: the rate of withdrawals, all due to exacerbations, was significantly lower during treatment with nedocromil sodium, whereas clinician opinion of treatment efficacy significantly favoured nedocromil sodium.

There are several explanations why treatment with nedocromil sodium in our patients with COPD failed to improve clinical parameters. It is possible that nedocromil sodium is not a potent anti-inflammatory agent in this patient group; however, if nedocromil sodium is effective the duration of treatment may have been too short, as has been suggested for other anti-inflammatory agents. ${ }^{4}$ The type of airway inflammation, which is different in asthmatics ${ }^{5}$ who generally respond better to anti-inflammatory medication, ${ }^{6}$ may also play a part. Instead of symptom scores, lung function, and airway responsiveness, other clinical parameters such as quality of life, decline in pulmonary function, or number and duration of exacerbations may be necessary to measure treatment efficacy in COPD. ${ }^{7}$ In this perspective our patients showed, in the short period of follow up, significantly fewer exacerbations when treated with nedocromil sodium. However, at the expense of treatment with nedocromil sodium, the higher withdrawal rate in the placebo group leads to selection bias, thus underestimating differences between placebo and nedocromil sodium treatment.
In conclusion, 10 weeks of treatment with a high daily dosage of nedocromil sodium did not improve pulmonary function, airway responsiveness, and clinical symptoms. The number of withdrawals, all due to exacerbations, was significantly greater in the placebo group than in the nedocromil sodium group. Longer trials will be necessary to determine whether nedocromil sodium reduces the frequency of exacerbations and the decrease in pulmonary function, eventually leading to a better quality of life in patients with COPD.

This work was supported by a grant from Fisons Plc, Pharmaceutical Division.

1 de Jong JW, Postma DS, de Monchy JGR, Koëter GH. A review of nedocromil sodium in asthma therapy. Eur Respir Rev 1993;15:511-9.

2 ATS. Standards for the diagnosis and care of patients with chronic obstructive pulmonary disease. Am Rev Respir Dis 1987;130:225-44.

3 Oosterhoff Y, de Jong JW, Jansen MAM, Koëter GH, Postma DS. Airway responsiveness to adenosine $5^{\prime}$-monophosphate in chronic obstructive pulmonary disease is determined by smoking. Am Rev Respir Dis 1993;147:553-8.

4 Auffarth B, Postma DS, de Monchy JGR, van der Mark ThW, Boorsma M, Koëter GH. Effects of inhaled budesonide on spirometric values, reversibility, airway responsiveness, and cough threshold in smokers with chronic obstructive lung disease. Thorax 1991;46:372-7.

5 Ollerenshaw SL, Woolcock AJ. Characteristics of the inflammation in biopsies from large airways of subjects with asthma and subjects with chronic airflow limitation. $\mathrm{Am}$ asthma and subjects with chronic
Rev Respir Dis 1992;145:922-7.

6 Juniper EF, Kline PA, Vanzieleghem MA, Ramsdale EH, O'Byrne PM, Hargreave FE. Long-term effects of budesonide on airway responsiveness and clinical asthma severity in inhaled steroid-dependent asthmatics. Eur Respir f 1990;3:1122-7.

7 Callahan CM, Dittus RS, Katz BP. Oral corticosteroid therapy for patients with stable chronic obstructive pulmonary disease. Ann Intern Med 1991;114:216-23.

\section{Effect of inhaled menthol on citric acid induced cough in normal subjects}

\author{
A H Morice, A E Marshall, K S Higgins, T J Grattan
}

Conclusions - Menthol is an effective antitussive agent in an evoked cough model.

(Thorax 1994;49:1024-1026)

University
Department of
Medicine and
Pharmacology, Royal
Hallamshire Hospital,
Sheffield S10 2JF, UK
A H Morice
A E Marshall
K S Higgins
T J Grattan
Reprint requests to:
Dr A H Morice.
Received 9 February 1994
Returned to authors
5 April 1994
Revised version received
7 June 1994
Accepted for publication
9 June 1994

\begin{abstract}
Background - Menthol is a commonly used ingredient in many over the counter cough remedies, but there is little objective evidence as to its efficacy.

Methods - Twenty healthy subjects received a cough challenge consisting of five inhalations of $33 \mu \mathrm{mol}$ citric acid from an air driven dosimeter. The challenge was repeated at hourly intervals for five hours. Five minutes before each challenge subjects inhaled, in a randomised design, either menthol $75 \%$ in eucalyptus oil or one of two placebos (pine oil or air).

Results - Menthol inhalation caused a reduction in evoked cough when compared with either placebo.
\end{abstract}

L-Menthol, a volatile aromatic compound, is the principal component of the essential oil derived from peppermint (Mentha piperita). L-Menthol and the synthetic racemate DLmenthol are included in a number of proprietary medicines sold for the treatment of symptoms due to the common cold.

In this study we have investigated the effect of menthol inhalation in a citric acid induced cough model and compared its effects with that of two placebo treatments, the first an inhaler 